\title{
Avoiding iatrogenic harm by integrating physical examination findings with a point-of-care lung ultrasonography
}

Sir,

A 50-year-old male presented to the hospital with the chief complaint of shortness of breath associated with high-grade fever and productive cough with a yellowish expectoration. He was confused, tachypnoeic and tachycardic, but without hypotension. Examination of the chest revealed right-sided basal coarse crepitations, but with equal air entry and normal percussion note. Trachea was central in location. Portable chest $X$-ray was suggestive of right-sided large pleural effusion, with blunting of costophrenic angle [Figure 1]. Laboratory investigations revealed elevated white blood count with neutrophil predominance and elevated blood urea level. Patient was admitted to Intensive Care Unit with the diagnosis of severe community acquired pneumonia with pleural effusion. Patient was started on injection Ceftriaxone and Azithromycin. Therapeutic thoracocentesis was planned. Chest X-ray findings did not correlate with the physical examination findings of chest. Bedside point-of-care the lung ultrasonography was performed by the intensivist. Multiple B-lines with increased lung water content was noted in right lower zone, but without pleural effusion [Figure 2]. Chest X-ray was repeated, which showed consolidation of right lower zone, but the costophrenic angle was visible. Thoracocentesis was deferred. With the suspicion of radiological artefact, the first chest X-ray was discussed with the radiologist.



Figure I: Chest X-ray suggestive of right-sided large pleural effusion with blunting of right costophrenic angle 


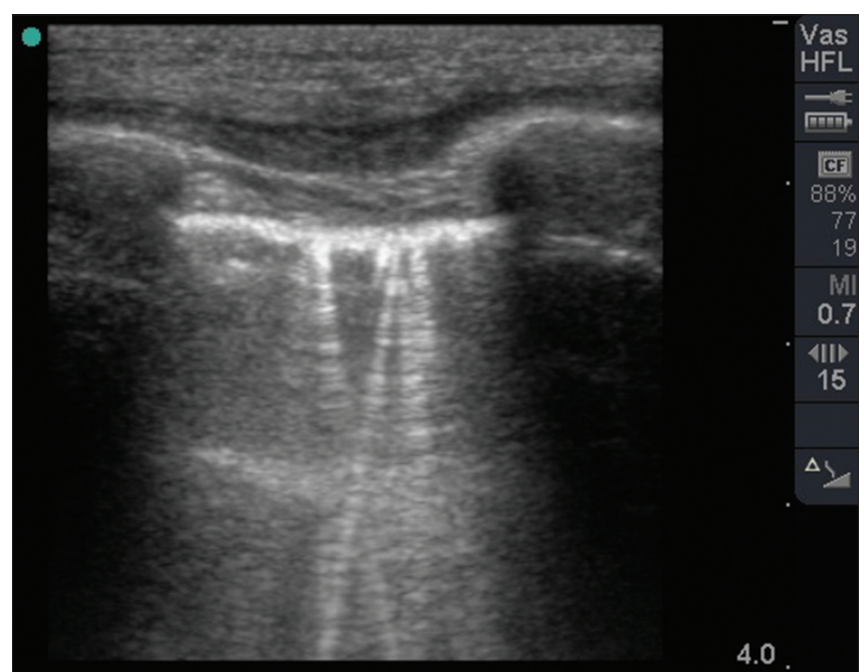

Figure 2: Lung ultrasound of right lower zone showing multiple B-lines with increased lung water content

The artefact was due to intensifying light exposure while positioning the $\mathrm{X}$-ray film.

Diagnostic errors are not uncommon and are potentially preventable. Procedural complications are an important cause of adverse events. ${ }^{[1]}$ It contributes to increased length of hospital stay, increased cost and higher morbidity. Minimizing iatrogenic harm is an important component of decreasing morbidity associated with critical care. It complies with one of the fundamental principles of ethics in critical care - nonmaleficence. ${ }^{[2]}$ The traditional chest physical examination alone is not sufficiently accurate to diagnose pneumonia. ${ }^{[3]}$ Point-of-care lung ultrasonography is helpful and accurate in diagnosing the cause of acute respiratory failure. ${ }^{[4]}$ The learning curve for acquiring skills to diagnose lung consolidation using a lung ultrasonography is steep. It can be attained in $<6$ weeks when performed on a daily basis. The intra and inter-observer variability is small and is $<5 \% .^{[5]}$ Iatrogenic pneumothorax is a common complication of the thoracocentesis, with overall rates of $6.0 \%$. Pneumothorax is more likely following therapeutic thoracocentesis. ${ }^{[6]}$

In our patient, by integrating the physical examination findings with a bedside point-of-care lung ultrasonography, we were able to avoid unnecessary thoracocentesis, averting the preventable and possible iatrogenic harm to the patient.

\section{Gentle Sunder Shrestha, Ananda Khanal' ${ }^{1}$, Sharad Paudel ${ }^{2}$}

Department of Anaesthesiology, Institute of Medicine, Tribhuvan University Teaching Hospital, Maharajgunj, ' Department of Critical Care Medicine,
Alka Hospital Pvt. Ltd. Jawalakhel, Kathmandu, ${ }^{2}$ Department of Critical Care Medicine, Nagarik Community Hospital, Bhaktapur, Nepa Correspondence:

Dr. Gentle Sunder Shrestha Department of Anaesthesiology, Institute of Medicine, Tribhuvan University Teaching Hospital, Maharajgunj, Kathmandu, Nepal. E-mail: gentlesunder@ hotmail.com

\section{References}

1. Leape LL, Brennan TA, Laird N, Lawthers AG, Localio AR, Barnes BA, et al. The nature of adverse events in hospitalized patients. Results of the Harvard Medical Practice Study II. N Engl J Med 1991;324:377-84.

2. Bledsoe TA, Levy MM. Basic ethical principles in critical care. In: Vincent JL, Abraham E, Moore FA, Kochanek PM, Fink MP, editors. Textbook of Critical Care. $6^{\text {th }}$ ed. United States of America: Saunders; 2011. p. 1573-5.

3. Wipf JE, Lipsky BA, Hirschmann JV, Boyko EJ, Takasugi J, Peugeot RL, et al. Diagnosing pneumonia by physical examination: Relevant or relic? Arch Intern Med 1999;159:1082-7.

4. Lichtenstein DA, Mezière GA. Relevance of lung ultrasound in the diagnosis of acute respiratory failure: The BLUE protocol. Chest 2008;134:117-25.

5. Bouhemad B, Zhang M, Lu Q, Rouby JJ. Clinical review: Bedside lung ultrasound in critical care practice. Crit Care 2007;11:205.

6. Gordon CE, Feller-Kopman D, Balk EM, Smetana GW. Pneumothorax following thoracentesis: A systematic review and meta-analysis. Arch Intern Med 2010;170:332-9.

\section{Access this article online}

Quick Response Code:

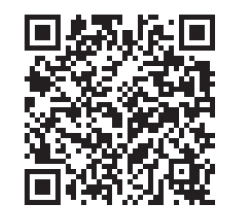

Website:

www.ijccm.org

DOI: $10.4103 / 0972-5229.154588$ 